\title{
Study on the Viscoelastic Property of Asphalt Rubber via Creep test
}

\author{
FENG Xiao-wei ${ }^{1, a}$, ZHANG Jun-ping ${ }^{2, b}$ \\ ${ }^{1}$ Gansu Provincial Transportation Research Institute Co., Ltd, Lanzhou 730050 \\ ${ }^{2}$ Northwest Research Institute Co., Ltd of C.R.E.C, Lanzhou 730000 \\ a361257121@qq.com, b1405270698@qq.com
}

Keywords: asphalt rubber; Laplace transform ; constitutive model;burgers model; creep test

Abstract : Viscoelastic properties is an important indicator to characterize the mechanical properties of materials, due to join a large number of crumb rubber makes viscoelastic properties of rubber asphalt are very different from other types of asphalt. In this paper, through theoretical analysis and Laplace transform deduced creep constitutive model of rubber asphalt BBR test, then based on the proposed model, carried on the BBR test under different conditions, and then established the constitutive model of rubber asphalt viscoelastic properties, by comparing the experimental and model, that the model can accurately characterize the viscoelastic properties of the rubber asphalt, and can provide guidance for the conduct of rubber asphalt relevant scientific research.

\section{Introduction}

Generally believed, asphalt material is a typical sticky, elastic and plastic complex. In the range of small deformations at lower temperature asphalt is very close to the line of elastomers, while in a wide range deformation of high temperature is manifested visco-plastic body, and in the normal temperature it takes look a general viscoelastic properties of the materials ${ }^{[1]}$. The cracking, rutting, fatigue and so on of asphalt pavement is closely related to the asphalt viscoelastic properties ${ }^{[2]}$, just temperature shrinkage cracks on asphalt pavement, the cracks occurred directly related to the low temperature crack resistance of asphalt materials and asphalt cement, while the U.S. SHRP plans to make the evaluation asphalt binder cracking resistance of bending beam rheological test BBR (Bending Beam Rheometer) and direct tensile test DTT (Direct Tension Test) is being increasingly accepted by scholars and engineering sectors ${ }^{[3]}$,among this two test the creep stiffness that obtained by BBR test for the evaluation of the performance of low-temperature asphalt binder are the key indicators.

Join some specially treated crumb rubber in asphalt and through certain processing formed asphalt rubber binder because of its numerous advantages such as can reduced traffic noise, thinning pavement thickness, delaying reflective cracking, avoid early damage, extend the pavement life has a good market prospect ${ }^{[4]}$. In the low-temperature performance, rubber asphalt can effectively reduce the creep stiffness and improve low temperature cracking resistance ${ }^{[5]}$. Based on the requirements of AASHTO T313-04, this paper carried out the BBR test at different temperautures to measure the creep stiffness of rubber asphalt, and combined with the modified Burgers model to characterize viscoelastic constitutive relations of rubber asphalt, deduced the thin beam creep rules under dead load through asphalt rubber BBR test, thus have a theoretical to the viscoelastic properties of asphalt rubber. 


\section{Raw materials and test}

\section{Raw materials}

(1) Crumb rubber. Select the 40 mesh crumb rubber of Plastic recycling (Suzhou) Co., Ltd.

(2) Asphalt. 90 A-class petroleum asphalt of Karamay.

(3) Asphalt rubber. Accordance the above asphalt and crumb rubber with $20 \%$ proportion, $190{ }^{\circ} \mathrm{C}$ reaction temperature, 60min reaction time, high-speed mixing production requirements produce asphalt rubber, the technical indicators are as follows in Table 1.

Table 1 The regions technical requirements of asphalt rubber

\begin{tabular}{ccccc}
\hline \multirow{2}{*}{ project } & \multicolumn{3}{c}{ Index requirements } & \\
\cline { 2 - 4 } & $\begin{array}{c}\text { cold } \\
\text { region } \\
\text { asphalt }\end{array}$ & $\begin{array}{c}\text { temperature } \\
\text { region } \\
90 、 90\end{array}$ & hot region & $\begin{array}{c}\text { measured } \\
\text { results }\end{array}$ \\
\hline $\begin{array}{c}110 、 90 \\
\text { (Pa.s) }\end{array}$ & $1.0 \sim 3.0$ & $2.0 \sim 4.0$ & $2.5 \sim 5.0$ & 2.8 \\
$\begin{array}{c}25^{\circ} \mathrm{Cpenetration} \\
(0.1 \mathrm{~mm})\end{array}$ & $60 \sim 100$ & $40 \sim 80$ & $30 \sim 70$ & 63 \\
softening point $\left({ }^{\circ} \mathrm{C}\right)$ & $>50$ & $>58$ & $>65$ & 68.5 \\
elastic recovery $(\%)$ & $>50$ & $>55$ & $>60$ & 61 \\
$5^{\circ} \mathrm{Cductility}(\mathrm{cm})$ & $>10$ & $>10$ & $>5$ & 11.0 \\
\hline
\end{tabular}

\section{Creep constitutive model of rubber asphalt BBR test}

According to the theory of elasticity, the trabecular span deflection through asphalt rubber BBR test is as follows:

$$
W=\frac{P L^{3}}{4 b h^{3} E}
$$

In the above formula:

$\mathrm{L}$ - trabecular $\operatorname{span}(\mathrm{mm})$;

b-trabecular width;

$\mathrm{h}$ - trabecular height $(\mathrm{mm})$;

$\mathrm{P}$ - constant $\operatorname{load}(\mathrm{mN}), \mathrm{P}=100 \mathrm{~g} \times 9.8 \mathrm{~N} / \mathrm{kg}=0.98 \mathrm{~N}=980 \mathrm{mN}$;

$\mathrm{E}$ - elastic modulus of the material(MPa).

Accordance with the corresponding laws of viscoelastic problems make Laplace transform to the above formula, we have:

$$
\bar{W}(s)=\frac{\overline{P L}^{3}}{4 b h^{3} E}
$$

$\overline{\mathrm{W}}$ (s) - deflection of the Laplace transform;

$\overline{\mathrm{P}}$ — concentrated load Laplace transform.

The formula for converting the viscoelastic formula, then we have:

$$
\bar{W}(s)=\frac{\bar{P} L^{3}}{4 b h^{3} E(s)}=\frac{L^{3}}{4 b h^{3}} \times \frac{P}{s} \times \frac{1+p_{1} s+p_{2} s^{2}}{q_{1} s+q_{2} s^{2}}
$$

Wherein $\mathrm{p}_{1}, \mathrm{p}_{2}, \mathrm{q}_{1}, \mathrm{q}_{2}$ is the same parameter. Make Laplace inverse transformation to the above 
equation:

$$
W=\frac{L^{3} P}{48 I} J^{-1}\left(\frac{1}{S} \times \frac{1+p_{1} s+p_{2} S^{2}}{q_{1} s+q_{2} s}\right)=\frac{L^{3} P}{48 I} J^{-1}[F(s)]
$$

In the above formula: $F(s)=\frac{1}{s} \times \frac{1+p_{1} s+p_{2} s^{2}}{q_{1} s+q_{2} s^{2}}=\frac{A(s)}{B(s)}$,

and $A(s)=1+p_{1} s+p_{2} s^{2}, B(s)=s\left(q_{1} s+q_{2} s^{2}\right)$,

since $s_{1}=0, s_{2}=\frac{p_{1}-\sqrt{p_{1}{ }^{2}-4 p_{2}}}{2 p_{2}}$ are the all odd points of function $\mathrm{F}(\mathrm{s})$, wherein $\mathrm{s}_{1}$ is the two zero, $s_{2}$ is the simple zero and A (s) and B (s) is irreducible polynomial, in accordance with stay calculation method:

$$
D(t)=\operatorname{Re} s\left[F(s) e^{s t}, s^{2}\right]+\lim _{s \rightarrow 0} \frac{d}{d_{s}}\left[s^{2} \times \frac{A(s)}{B(s)} e^{s t}\right]
$$

Of the above equation $\mathrm{D}(\mathrm{t})=\mathrm{J}^{-1}[\mathrm{~F}(\mathrm{~s})], \mathrm{F}$ (s) is the creep compliance that got by anti-Laplace transform, $\operatorname{Res}\left[\mathrm{F}(\mathrm{s}) \mathrm{e}^{\mathrm{st}}, \mathrm{s}^{2}\right]$ is the residue that complex function $\mathrm{F}(\mathrm{s}) \mathrm{e}^{\mathrm{st}}$ at singular point $\mathrm{s}=\mathrm{s}_{2}$, to simplification the above equation can get asphalt rubber BBR trabecular creep stiffness modulus:

$$
S(t)=\frac{1}{D(t)}=\frac{P(t) L^{3}}{4 b h^{3} W(t)}
$$

\section{BBR test results}

First asphalt rubber will conduct rotate asphalt filmy heating operational test for $75 \mathrm{~min}$ under a condition of $163^{\circ} \mathrm{C}\left(\mathrm{RTFOT}\right.$ aging), and then let RTFOT sample at $100{ }^{\circ} \mathrm{C}, 2.1 \mathrm{MPa}$ pressure of a $20 \mathrm{~h}$ aging test(PAV aging). Next, make asphalt rubber of PAV sample into asphalt trabecular of a size $127 \mathrm{~mm}(\mathrm{~L}) \times 12.7 \mathrm{~mm}(\mathrm{~b}) \times 6.35 \mathrm{~mm}(\mathrm{~h})$, conduct creep test under different temperatures $\left(\mathrm{T}=-6{ }^{\circ} \mathrm{C}\right.$, $\mathrm{T}=-12{ }^{\circ} \mathrm{C}, \mathrm{T}=-18{ }^{\circ} \mathrm{C}, \mathrm{T}=-24{ }^{\circ} \mathrm{C}, \mathrm{T}=-30{ }^{\circ} \mathrm{C}$ ), creep stiffness modulus is calculated by the formula (6), were obtained $8.0 \mathrm{~s}, 15 \mathrm{~s}, 30 \mathrm{~s}, 60 \mathrm{~s}, 120 \mathrm{~s}, 240 \mathrm{~s}$ creep test results, specific results as follows:

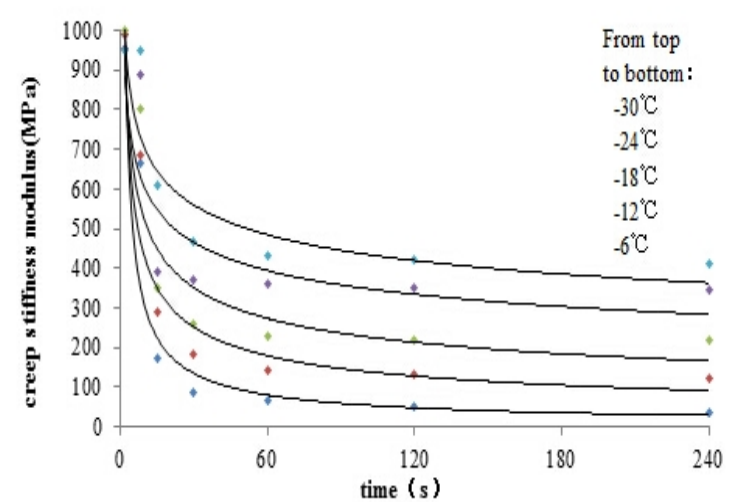

Fig 1 Creep stiffness modulus changes with temperature and time

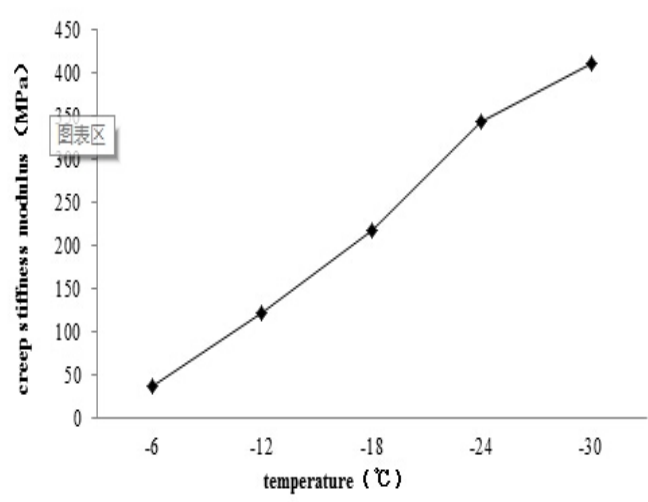

Figure 2 Creep stiffness modulus variation trend with temperature

As can be seen, with the temperature change asphalt rubber creep stiffness modulus is gradually increased, at the same time in different temperatures with the time increase, the creep stiffness modulus attenuate rapidly at first(about 30s), gradually stabilized subsequently. 


\section{Establishment of asphalt rubber viscoelastic constitutive model}

According to the model theory of rheology, sticky, elastic, plastic is the most basic understanding of the mechanical unit, this base unit with a certain mechanical model and its constitutive relation to express, it is known as mechanical components ${ }^{[7]}$. By different combinations of series and parallel, the mechanical elements form a more complex combinational model to effectively reflect the actual mechanical properties of the material. For an ideal elastic material, the stress - strain relationship satisfies the Hooke 's law, stress $\sigma$ and strain $\varepsilon$ a linear relationship; for an ideal viscous material satisfy the laws of Newtonian flow, stress $\sigma$ and strain rates $\mathrm{d} \varepsilon$ /dt constitute a linear relationship, and for a viscoelastic material it can be assumed that the stress $\sigma$ and $\mathrm{d}^{\mathrm{r}} \varepsilon / \mathrm{dt}^{\mathrm{r}}(0<\mathrm{r}<1)$ a linear relationship ${ }^{[8]}$. Common model for the analysis of asphalt have Maxwell viscoelastic model, Kelvin model, Zener model, Burgers model. In these models due to Burgers model can better reflect the deformation characteristics of asphalt (especially in the loading process), so it widely used to analyze the viscoelastic properties of the material ${ }^{[9]}$. The modified Burgers model was linear correction the first element Burgers model, ie $\eta_{1}=\mathrm{Ae}^{\mathrm{Bt}}$, as in Figure 3, other equations same to the Burgers model, and therefore more representative, in this paper we select modified Burgers model to analysis the viscoelastic properties of asphalt rubber.

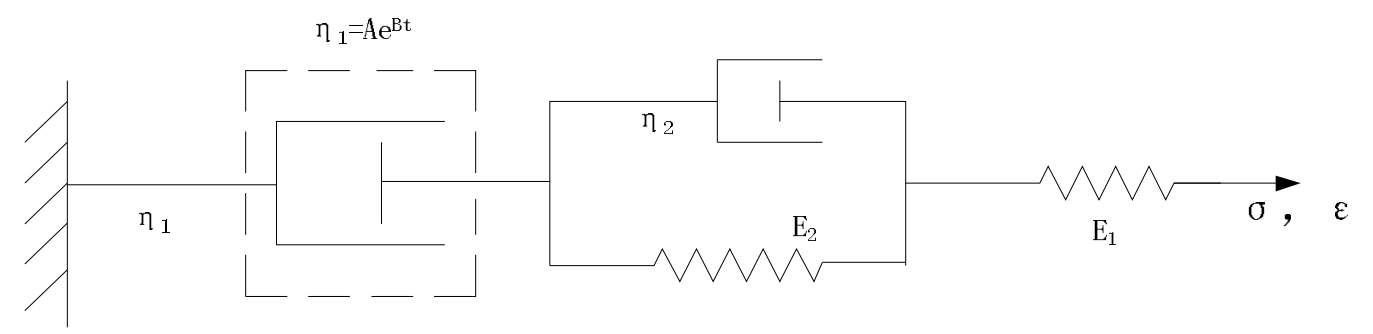

Fig 3 The modified Burgers model

As above figure, the mechanical components deformations of modified Burgers model include three parts: elastic deformation, viscous deformation and viscoelastic deformation $\left[{ }^{10]}\right.$, the constitutive equations model is: ;

$$
\sigma+p_{1} \propto \alpha+p_{2} \propto \alpha=q_{1} \&+q_{2} \& \mathcal{\&}
$$

In the above formula: $\mathrm{p}_{1}=\eta_{1} / \mathrm{E}_{1}+\left(\eta_{1}+\eta_{2}\right) / \mathrm{E}_{2} ; \mathrm{p}_{2}=\eta_{1} \eta_{2} / \mathrm{E}_{1} \mathrm{E}_{2} ; \mathrm{q}_{1}=\eta_{1} ; \mathrm{q}_{2}=\eta_{1} \eta_{1} / \mathrm{E}_{2}$.

From the Boltzmann superposition principle it can obtain integral constitutive relation:

$$
\varepsilon(t)=\sigma_{0} S(t)+\int_{0}^{t} T(t-\xi) \frac{d \sigma(\xi)}{d \xi} d \xi
$$

$\mathrm{S}(\mathrm{t})$ is the creep stiffness modulus, to modified Burgers model its creep stiffness modulus $\mathrm{S}(\mathrm{t})$ as follows:

$$
S(t)=\frac{1}{E_{1}}+\frac{t}{\eta_{1}}+\frac{1}{E_{2}}\left[1-\exp \left(-\frac{t}{\tau}\right)\right]
$$

In the above formula $\tau=\eta_{2} / E_{2}, \eta_{1} 、 E_{2} 、 \eta_{2}$ is the viscoelastic parameters of the model.

\section{Comparative analysis of experimental results with theoretical models}

Based on the above analysis, take $-24{ }^{\circ} \mathrm{C}$ as example, compare to SHRP trabecular bending test results with the modified Burgers rheological model results, the results shown in Table 2. 
Table 2 The test results and model comparison

\begin{tabular}{ccccc}
\hline $\mathrm{t} / \mathrm{s}$ & $\mathrm{p} / \mathrm{mN}$ & $\varepsilon / \mathrm{mm}$ & $\begin{array}{c}\text { BBR stiffness modulus } \\
\text { of the resulting test } \\
(\mathrm{MPa})\end{array}$ & $\begin{array}{c}\text { Stiffness modulus of the } \\
\text { resulting rheological } \\
\text { model (MPa) }\end{array}$ \\
\hline 8 & 985 & 0.012 & 658 & 664 \\
15 & 980 & 0.115 & 424 & 421 \\
30 & 986 & 0.164 & 370 & 379 \\
60 & 982 & 0.203 & 361 & 359 \\
120 & 982 & 0.235 & 357 & 363 \\
240 & 980 & 0.284 & 344 & 347 \\
\hline
\end{tabular}

Take Origin 6.0 nonlinear curve fitting function to fitting BBR test results under $-24^{\circ} \mathrm{C}$ and rheological model results which use Levenberg-Marquardt method of least squares method, relevant results as follows.

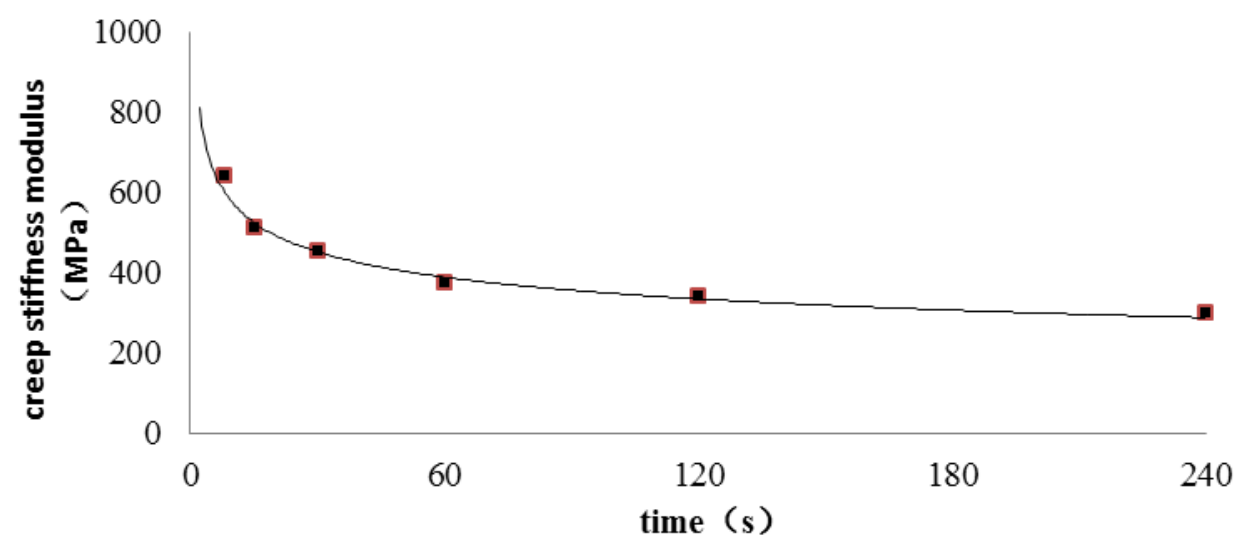

Fig 4 The BBR test results and model curve fitting under $-24^{\circ} \mathrm{C}$

From above it can be seen that BBR test results and the model curve curves shows have a very good correlation, their correlation coefficient of 0.992, so use Burgers model analysis viscoelastic properties of rubber asphalt has a good feasibility and rationality.

\section{Conclusions}

In this paper, it can be said through creep test to analysis the viscoelastic properties of asphalt rubber, obtained the following conclusions:

(1) According to the characteristics of rubber asphalt established creep constitutive model of the BBR trabecular trial and chose modified rubber asphalt Burgers model to characterize the constitutive model.

(2) Through rubber asphalt trabecular creep tests at different temperatures, obtained creep stiffness modulus curve of rubber asphalt at different temperatures. It also known with the temperature change asphalt rubber creep stiffness modulus is gradually increased, at the same time in different temperatures with the time increase, the creep stiffness modulus attenuate rapidly at first(about 30s), gradually stabilized subsequently.

(3) By comparing the results with BBR test at $-24{ }^{\circ} \mathrm{C}$ of asphalt rubber and modified Burgers model, indicate that selected rheological model can feasible, reasonable simulate the actual creep test results, and can be more truly reflect the viscoelastic properties of rubber asphalt.

\section{References}

[1] JTG/T F50-2011 Guide for design and construction of asphalt rubber and mixtures [M]. Beijing: 
People's Communications Press, 2008.12. (in Chinese)

[2] Huang Peng, Lv Weimin. Rubber powder modified asphalt mixture performance and technology research [J]. China Journal of Highway, 2001, 3(12):21-24. (in Chinese)

[3] Wang Xudong, Li Meijiang. The Applied Technology of the Crumb Rubber in the Asphalt and Mixture[M]. Beijing: People's Communications Press, 2008. (in Chinese)

[4] Zhang Xiaoning. Viscoelastic principle experiment [M]. Harbin: Harbin Shipbuilding Engineering Institute Press, 1990. (in Chinese)

[5] Yang Tingqin. Viscoelasticity [M] . Wuhan: Huazhong university of science and technology press, 1990. (in Chinese)

[6] Christensen R M. Theory of viscoelasticity: an introduction [M].New York:Academic Press, Inc. 1982

[7] Xu Shifa. Rheological characterization of asphalt and asphalt mixture model high temperature creep properties [J].Mechanics in Engineering, 1992,14(1):37-40. (in Chinese)

[8] Zheng Jianlong, Lv Songtao, Tian Xiaoge. Viscoelastic damage characteristics of asphalt based on creep test[J]. Engineering Mechanics, 2008, 25(2):193-196. (in Chinese)

[9] Chaboche J L.Continuum damage mechanics, part I and part II [J] .ASME, Journal of Applied Mechanics,1998,55:59—72.

[10] Zhan Xiaoli. Research on the viscoelastic properties of asphalt using DMA[D].Harbin: Harbin Institute of Technology,2007:35 80. (in Chinese).

[11] Sun Haizhong, Zhang Wei. Study on constitutive relation of viscoelastic material described by fractional operator [J]. Journal of Materials Science and Engineering,2006,24 (6):926-93. (in Chinese). 